\title{
DE CASTIZAR A DISPARAR O ¿CÓMO HABLAN LOS GUINEOECUATORIANOS EL ESPAÑOL? TERMINOLOGÍA METALINGÜÍSTICA Y REFLEXIONES TEÓRICO-IDEOLÓGICAS A PARTIR DE UN CORPUS DE ENTREVISTAS SOCIOLINGÜÍSTICAS
}

\author{
FROM CASTIZAR TO DISPARAR OR: HOW DO EQUATOGUINEANS SPEAK \\ SPANISH? METALINGUISTIC TERMINOLOGY AND THEORETICAL-IDEOLOGICAL \\ INTERPRETATIONS BASED ON A CORPUS OF SOCIOLINGUISTIC INTERVIEWS
}

\author{
Sandra Schlumpf \\ Universität Basel \\ sandra.schlumpf@unibas.ch
}

\begin{abstract}
RESUMEN
A pesar del creciente interés por Guinea Ecuatorial que se observa en el ámbito académico, en los estudios de lingüística hispánica sigue teniendo una representación bastante limitada y un estatus más bien marginal. También en la lexicografía española, Guinea Ecuatorial ha recibido poca atención, pese a la existencia indudable de voces y acepciones propias que caracterizan la variedad guineoecuatoriana del español. En este artículo, ofrecemos un acercamiento crítico a la posición excéntrica que ocupa el léxico guineoecuatoriano en la lingüística hispánica tradicional. Para ello, nos basamos en un corpus de 24 entrevistas sociolingüisticas que hemos realizado en Madrid con personas de origen guineoecuatoriano. En concreto, estudiamos una selección de términos metalingüísticos empleados por las personas entrevistadas que hacen referencia a cómo los guineoecuatorianos hablan el español: los verbos castizar, inculcar, disparar y chapurrear, y los sustantivos disparate(s) y guineo / guineo. Además, incluimos un excurso sobre la aparición de los conceptos lingüísticos lengua, idioma y dialecto. Todos los términos estudiados se ejemplifican mediante extractos ilustrativos de las entrevistas. El principal interés del estudio reside en la combinación del análisis léxico-semántico de los términos mencionados con una posterior interpretación teórico-ideológica de los resultados. Este acercamiento múltiple nos permite observar, a partir de una serie de vocablos concretos, varios desafíos que caracterizan la dialectología hispánica tradicional y que se reflejan, asimismo, en la lexicología. En particular, llamamos la atención sobre la problemática de estudiar variedades más excéntricas de la lengua a partir de unas pautas de análisis, teorías e ideologías construidas en torno a variedades consideradas más "estándares" y "normativas" que otras.
\end{abstract}

Palabras clave: español, Guinea Ecuatorial, Madrid, lexicografía, guineanismos léxicos, entrevistas sociolingüísticas, terminología metalingüística, multilingüismo, jerarquías lingüísticas, lengua, dialecto.

\begin{abstract}
Despite the increasing interest in Equatorial Guinea observed in the academic field, it continues to have a quite limited representation and a rather marginal status in Hispanic linguistic studies. In Spanish lexicography, Equatorial Guinea has received little attention too, despite the undoubted existence of unique words and meanings which characterise the Equatoguinean variety of Spanish. In this article, we offer a critical approach to the eccentric position that the Equatoguinean lexicon occupies in traditional Hispanic linguistics. To do so, we base on a corpus of 24 sociolinguistic interviews conducted in Madrid with people of Equatoguinean origin. In special, we study a selection of metalinguistic terms used by the interviewees that refer to how Equatoguineans speak Spanish: the verbs castizar, inculcar, disparar and chapurrear, as well as the nouns disparate(s) and guineo / guineo. In addition, we include an excursus on the appearance of the linguistic concepts lengua, idioma and dialecto. All the terms studied are exemplified by illustrative excerpts from the interviews. The main interest of the study lies in the combination of the lexical-semantic analysis of the terms mentioned with a subsequent theoretical-ideological interpretation of the results. Starting from a series of concrete words, this multiple approach allows us to observe various challenges which characterise traditional Hispanic dialectology and which are also reflected in lexicology. In particular, we draw attention to the problems faced when studying more eccentric varieties of the language on the basis of analytical guidelines, theories and ideologies built around varieties considered more "standard" and "normative" than others.
\end{abstract}

Keywords: Spanish, Equatorial Guinea, Madrid, lexicography, lexical guineanisms, sociolinguistic interviews, metalinguistic terminology, multilingualism, linguistic hierarchies, language, dialect. 


\section{INTRODUCCIÓN}

El español hablado en Guinea Ecuatorial representa, sin dudas, una variedad excéntrica de la lengua española: Guinea Ecuatorial se encuentra en la periferia geográfica del mundo hispanohablante, ocupa una posición marginal en los imaginarios e ideologemas construidos en torno al mundo hispánico y el español guineoecuatoriano sigue careciendo de una descripción dialectológica comparable a la de otras variedades de la lengua española. En el ámbito del léxico, la situación es similar: hasta hoy, la representación del léxico guineoecuatoriano en las obras lexicográficas del español es anecdótica. En concreto, el Diccionario de la lengua española (DLE) (2020) solo recoge unas 30 entradas que llevan la marca Guin. (Guinea Ecuatorial). De ellas, la mayoría son términos que presentan algún uso particular conocido también en otras variedades del español (por ejemplo, bananal, beneficiar, chapear, malanga o palmiste), mientras que otros tienen una acepción usada únicamente en Guinea Ecuatorial (acompañante, apear, boy, envuelto, jefe tradicional, lluvioso/sa) o, incluso, solo se emplean en el español guineoecuatoriano (abaá, grombif, malamba, mangüeña, misis). Además de estos guineanismos léxicos, el DLE (2020) recoge una serie de términos que designan realidades guineoecuatorianas. Entre estos últimos, destacan los pueblos autóctonos de Guinea Ecuatorial y sus respectivas lenguas (annobonés, benga, bubi, fang, ndowé, pamue), además de unos pocos vocablos sueltos (clote, cumbé, ekuk). No cabe duda de que hay bastantes más palabras que son características del español de Guinea Ecuatorial o que conocen alguna acepción propiamente guineoecuatoriana, sin que estos usos quedasen reflejados en el Diccionario.

La finalidad de este artículo es reflexionar sobre ciertos lexemas empleados por hablantes guineoecuatorianos del español que posiblemente reflejen rasgos propios de su variedad. El interés especial de la selección de los términos analizados en esta ocasión reside en el hecho de que no solo permite 
estudiar ciertos usos léxico-semánticos particulares, sino que estos últimos se pueden poner en relación con las valoraciones que hacen los propios hablantes de su español excéntrico. Se trata, por lo tanto, de un estudio cualitativo, cuyo principal logro reside en la combinación de un análisis léxico-semántico con una interpretación teórico-ideológica.

En lo que sigue, primero presentamos el corpus de entrevistas en el que nos basamos para el posterior análisis. Se trata de un corpus de 24 entrevistas sociolingüísticas realizadas con personas de origen guineoecuatoriano en Madrid, España (ver apartado 2). A continuación, presentamos el estudio de una selección de términos que permiten describir y caracterizar la forma en que los guineoecuatorianos hablan, no hablan o deberían hablar el español (apartado 3). Los términos estudiados son los siguientes: los verbos castizar, inculcar, disparar y chapurrear, así como los sustantivos disparate(s) y guineo / guíneo. Reflejamos su uso en las entrevistas con la ayuda de ejemplos concretos, presentamos los contextos temáticos en los que aparecen y aportamos información lexicográfica pertinente. En el apartado 4, a su vez, ofrecemos unas reflexiones teóricas e ideológicas en torno a los términos estudiados, que nos llevan de nuevo a la cuestión de la posición y valoración del español guineoecuatoriano en el conjunto de las variedades de la lengua española. En el mismo apartado, incluimos un resumen de la aparición en las entrevistas de los tres conceptos lingüísticos lengua, idioma y dialecto, y reflexionamos sobre su empleo para hacer referencia a las lenguas africanas. Cerramos el estudio con unas breves observaciones finales.

\section{CARACTERÍSTICAS E INTERÉS DEL CORPUS}

Para el análisis que presentamos en este trabajo, nos basamos en un corpus de 24 entrevistas sociolingüísticas que hemos realizado entre 2017 y 2018 con personas de origen guineoecuatoriano (esto es, personas nacidas en Guinea Ecuatorial) que residían, en el momento de las entrevistas, en la Comunidad 
de Madrid $^{1}$. El colectivo de guineoecuatorianos en España, y particularmente en Madrid, tiene especial interés debido a motivos históricos y demográficos. La diáspora guineoecuatoriana en España es la mayor fuera del propio país y, dentro de España, en Madrid se encuentra el mayor contingente: según el Instituto Nacional de Estadística (2020), a fecha de 1 de enero de 2020, 23.594 personas nacidas en Guinea Ecuatorial vivían en España, de las que casi el 40\% (9.085 personas) residían en la Comunidad de Madrid. Se trata de una comunidad de gran arraigo en la sociedad española, dado que el auge de las migraciones guineoecuatorianas hacia España data de los años 70 del siglo xx, época de la primera dictadura en Guinea Ecuatorial (régimen de Francisco Macías Nguema, 1968-1979). Hoy en día, muchos de los guineoecuatorianos que viven en España llevan ya bastantes años allí o tienen familiares o conocidos con una vida arraigada en España desde hace mucho tiempo ${ }^{2}$. En concreto, las 24 personas entrevistadas llevan entre 1,5 y 23 años viviendo en la Comunidad de Madrid (la mitad de ellas máximo 8 años, la otra mitad más de 8 años), tienen entre 17 y 48 años de edad, y se dividen de forma equilibrada entre mujeres y hombres, así como entre las dos etnias principales de Guinea Ecuatorial, los bubis y los fang.

Dicho corpus es de gran relevancia para la lingüística hispánica, dado que se trata de las primeras entrevistas sociolingüísticas realizadas con guineoecuatorianos en España. Son entrevistas semidirigidas, compuestas por relatos de vida, que duran, por término medio, unos 60 minutos. El hilo rojo de las

\footnotetext{
${ }^{1}$ Las estancias de investigación se pudieron llevar a cabo gracias a una beca del Fondo Nacional Suizo de Investigaciones Científicas (Proyecto 173468: "Sociolinguistic integration of immigrants from Equatorial Guinea in Madrid", http://p3.snf.ch/project-173468) y una beca de investigación "Giner de los Ríos" de la Universidad de Alcalá. La posterior digitalización y lematización de las entrevistas transcritas fue realizada con el apoyo de Anđelka Zečević de la Universidad de Belgrado durante una colaboración científica financiada por el Fondo Nacional Suizo de Investigaciones Científicas (Proyecto 190022: "Digital analysis of sociolinguistic data. Linguistic features in interviews with Spanish speakers from Equatorial Guinea", http://p3.snf.ch/project-190022).

${ }^{2}$ Para más detalles acerca de la comunidad de guineoecuatorianos en Madrid, véase Schlumpf (en prensa).
} 
entrevistas es la experiencia migratoria de las personas entrevistadas y su vida actual en Madrid, sin embargo, en diferentes momentos de las entrevistas, las preguntas versan sobre aspectos de índole sociolingüística y dialectológica. Por lo tanto, las entrevistas constituyen un corpus único que ofrece información acerca de la experiencia de vida de los guineoecuatorianos en España y, además, de su percepción y sus actitudes frente a diferentes variedades de la lengua española y frente a las otras lenguas de Guinea Ecuatorial, especialmente, las lenguas bantúes (bubi, fang, etc.), el pichi y el fá d'ambô. Al mismo tiempo, las grabaciones y las transcripciones de las entrevistas permiten analizar características lingüísticas del español hablado por los guineoecuatorianos en España, especialmente en el nivel fonético, morfosintáctico y léxico.

Hasta el momento, se han realizado análisis sociolingüísticos, morfosintácticos, léxicos e ideológicos, cuyos principales resultados se han presentado en congresos internacionales y se han publicado en diferentes revistas (Schlumpf, 2018, 2020a, 2020b, en prensa a, en prensa b). En el caso concreto del léxico, la extensión del corpus permite realizar análisis cualitativos, cuya relevancia resalta particularmente cuando se trata de términos de interés no solo lexicológico o lexicográfico, sino también de interés histórico, sociolingüístico o ideológico. Es por este motivo que, para esta contribución, hemos seleccionado una serie de términos que hacen referencia, de un modo u otro, a cómo los guineoecuatorianos hablan (o no hablan) o deberían hablar el español. Esto nos permite combinar un análisis léxico-semántico (apartado 3) con reflexiones de carácter teórico-ideológico (apartado 4). En la sección 4, además, incluiremos el resumen de la aparición en las entrevistas de los tres términos lengua, idioma y dialecto, centrándonos en cómo se distribuye su empleo cuando se refieren a las lenguas africanas de Guinea Ecuatorial. En suma, los términos analizados en este trabajo nos permiten acercarnos a la percepción y las actitudes lingüísticas de las personas entrevistadas hacia su propia forma de hablar el español, un tema de gran importancia para entender cómo se posicionan los hablantes guineoecuatorianos del español dentro del mundo hispanófono. 


\section{ANÁLISIS LÉXICO-SEMÁNTTICO}

Como ya hemos adelantado, el análisis léxico-semántico que presentamos a continuación gira en torno a una pequeña selección de términos (verbos y sustantivos) que están relacionados con la forma guineoecuatoriana de hablar el español. Todos ellos han provocado nuestra atención durante el análisis de las entrevistas porque reflejan, por un lado, un uso léxico particular del habla guineoecuatoriana y, por otro, transmiten una opinión sobre esta variedad del español. En su conjunto, el análisis de los vocablos estudiados nos puede dar una idea de cómo los propios guineoecuatorianos se perciben como hispanohablantes y cómo valoran su propia forma de hablar el español. El orden en que tratamos los términos corresponde a la estructura temática del trabajo.

La tabla 1 muestra los términos seleccionados, el total de sus ocurrencias en las entrevistas, así como el número de entrevistas en las que se usan. Tanto el número absoluto de ocurrencias como la distribución en el corpus de entrevistas nos vuelven a recordar el carácter cualitativo de este estudio. No obstante, creemos que las tendencias que observamos son características para el español guineoecuatoriano en su conjunto y que las conclusiones a las que llegamos tienen relevancia para entender mejor y replantear el papel que juega Guinea Ecuatorial como parte del mundo hispanohablante.

\begin{tabular}{|c|c|c|}
\hline Términos analizados & $\begin{array}{l}\text { Ocurrencias en las } \\
\text { entrevistas }\end{array}$ & $\begin{array}{l}\text { Número de entrevistas en las que } \\
\text { aparecen los términos }\end{array}$ \\
\hline castizar (verbo) & 11 & 3 (entrevistas 13_-8HF, 16_-8MF y 22_+8MF) \\
\hline inculcar (verbo) & 18 & $\begin{array}{l}5 \text { (entrevistas } 01 \_-8 \mathrm{HB}, 02 \_-8 \mathrm{HB}, 07 \_+8 \mathrm{HB} \text {, } \\
\left.14 \_-8 \mathrm{HF} \text { y } 15 \_-8 \mathrm{HF}\right)\end{array}$ \\
\hline disparar (verbo) & 2 & 2 (entrevistas $05 \_-8 \mathrm{MB}$ y $\left.19 \_+8 \mathrm{HF}\right)$ \\
\hline disparate(s) (sust.) & 5 & 3 (entrevistas 02_-8HB, 17_-8MF y 19_+8HF) \\
\hline guineo (sust.) & 20 & 1 (entrevista 13_-8HF) \\
\hline guineo (sust.) & 2 & 1 (entrevista 19_+8HF) \\
\hline chapurrear (verbo) ${ }^{3}$ & 3 & 1 (entrevista 02_-8HB) \\
\hline
\end{tabular}

${ }^{3}$ El verbo chapurrear se comentará en el apartado dedicado a guineo / guíneo. 
En lo que sigue, comentamos el uso de estos términos en las entrevistas, los ejemplificamos mediante pasajes ilustrativos y los ponemos en relación con las definiciones que aparecen en diferentes diccionarios de la lengua española. Todo ello nos servirá para reflexionar sobre la posición de Guinea Ecuatorial como país hispanohablante y para formular una serie de observaciones de carácter teórico e ideológico en el apartado 4.

\subsection{CASTIZAR}

es que es raro / es una estupidez que te encuentres con un guineano que no sepa castizar es un ignorante de por vida h porque tiene que saber castizar está obligado a castizar (16_-8MF)

Empecemos con el único de los términos comentados en este trabajo que no está registrado en el DLE: el verbo castizar ${ }^{5}$ Encontramos, en total, 11 ocurrencias de castizar en nuestro corpus, de ellas 7 infinitivos, 3 presentes de indicativo (castizan) y 1 gerundio (castizando). Se trata de un guineanismo léxico de uso propio en Guinea Ecuatorial. Ya lo recogen Antonio Quilis y Celia Casado-Fresnillo (1995, pp. 329-330) en su amplia monografía La lengua española en Guinea Ecuatorial como ejemplo de guineanismo y arcaísmo. Los autores lo usan para ejemplificar las "palabras españolas arcaicas que han adquirido una especialización en su significado" (Quilis \& Casado-Fresnillo, 1995, p. 329) y proponen, como definición, 'hablar bien el español' (Quilis \&

\footnotetext{
${ }^{4}$ Todos los ejemplos que se citan a lo largo de este trabajo forman parte del corpus núcleo de entrevistas realizadas entre 2017 y 2018 por Sandra Schlumpf con guineoecuatorianos en la Comunidad de Madrid. Los ejemplos se presentan en su versión transcrita sin etiquetas según PRESEEA (cfr. http://preseea.linguas.net/Portals/0/Metodologia/Marcas etiquetas minimas obligatorias 1 2.pdf), con ligeras adaptaciones. Se indican citas (“..."), alargamientos (:), palabras cortadas (-), pausas breves (/) y más largas (//), inhalaciones cortas (.h) e inhalaciones largas (.h:); las palabras señaladas en letra cursiva corresponden a los términos analizados en este estudio. Los códigos indicados al final de cada cita contienen la siguiente información: número de la entrevista (01-24), tiempo de estancia de la persona en Madrid $(-8=$ hasta 8 años $/+8=$ más de 8 años), sexo $(H=$ hombre $/ M=$ mujer $)$ y etnia (B $=$ bubi $/ \mathrm{F}=$ fang $)$.

5 Tampoco aparece en los demás diccionarios consultados salvo en el DAmer (2010), pero con una asociación diferente a la que vemos reflejada en nuestros ejemplos: 'Aparear alguien animales de distintas razas' (DAmer, 2010, s.v. castizar). Asimismo, el verbo se conoce en gallego (castizar) y en portugués (castiçar).
} 
Casado-Fresnillo, 1995, p. 371). Vuelve a citarlo Casado-Fresnillo en otro trabajo, enumerándolo bajo guineanismos — “que sólo se emplean en Guinea con unos rasgos peculiares que, poco a poco, han ido perfilando un léxico propio y característico" (Casado-Fresnillo, 1998, p. 85)—, como ejemplo de una formación léxica. Añaden Quilis y Casado-Fresnillo (1995, p. 371) que castizar "[a]lterna con el menos frecuente castellanizar", verbo que no aparece en nuestras entrevistas.

Veremos que la definición de castizar propuesta por Quilis y Casado-Fresnillo se refleja, asimismo, en nuestro corpus. En concreto, encontramos el empleo del verbo castizar en diferentes contextos temáticos:

La idea de Guinea Ecuatorial como país hispanófono y, de ahí, la importancia de que los guineoecuatorianos sepan hablar (bien) el español. Veamos dos pasajes de una entrevista:

(1) me acuerdo una vez que mi padre nos prohibió no volver a usar el fang h y [...] como que: [...] o:bligatoriamente teníamos que aprender a castizar y: / le agradezco.$h$ en principio me parecía mal pero ahora h: es lo mejor que me ha podido pasar pero es imagínat- digamos yo llego aquí [a Madrid] y no me sé castizar / y o sea / todo se pondría peor que de lo que estoy pasando (16_-8MF)

(2) es que es raro / es una estupidez que te encuentres con un guineano que no sepa castizar es un ignorante de por vida h porque tiene que saber castizar está obligado a castizar (16_-8MF)

Según nos relata esta chica, su padre le prohibió usar el fang en casa porque quería que sus hijos aprendiesen a castizar, o sea, a hablar en castellano. De hecho, como aún veremos, varias personas entrevistadas valoran de forma negativa el uso paralelo del español y de las lenguas africanas, así como sus posibles consecuencias en forma de fenómenos de contacto lingüístico (ver apartado dedicado a los disparates). En concreto, parece existir la opinión de que el uso del fang puede tener consecuencias negativas para el aprendizaje y el empleo correcto (castizo) del castellano.

b. La alusión a las posibles diferencias internas en el español de Guinea Ecuatorial, que se trasladan a las distintas formas de castizar la lengua: 
(3) .h: bueno los que están en la isla / que están en Malabo [...] que han esta- en la de que e:s la capital entonce:s h eh yo yo creo que cas- eeh castizan bien más mejor / que los que está:n ahí: digamos en: Evinayo:ng Ebebiyín por ahí / .h: porque ahí tendrán un acento así: h: hm que: sí habla español pero que no lo pronuncia tan bien tan bien tan bien (22_+8MF)

Aquí es interesante notar que castizar no simplemente significa 'hablar bien el español', sino que puede haber variación de nivel: alguien puede castizar mejor o peor (ver también ejemplo 23 infra: "estás castizando muy mal", 13_-8HF). En concreto, las diferencias se asocian con una oposición entre el español hablado en la isla de Bioko, particularmente en la capital del país (Malabo), y el español hablado en Río Muni, la parte continental de Guinea Ecuatorial, sobre todo en zonas rurales y regiones alejadas de la costa. Esta supuesta diferenciación diatópica en el dominio del español se refleja, asimismo, en las valoraciones de otras personas entrevistadas (ver la próxima cita y el ejemplo 14 infra: "los del continente lo hablan / fatal // todos no estoy segura pero: la gran mayoría lo hablan / muy mal muy mal”, 05_-8MB):

(4) pues / eeh en la isla / por ejemplo / .h: en Malabo se habla español hmmm del uno al diez hmm cuatro y medio a lo mejor [...] aceptable / .h no bueno pero aceptable .h: en los pueblos eeeh sobre todo los pueblos que está:n pegados a la capital / se: contagiaron hm ese nivel / pero los que están más alejados .h: el español: eh / se habla podríamos bajar a un tres pero se habla [...] en la parte continental / hay zonas donde no se habla español [...] porque la gente no sabe hablar español (09_+8HB)

Teniendo en cuenta la diversidad étnica de la población de Guinea Ecuatorial y su distribución tradicional en las diferentes zonas del país, estas opiniones se pueden poner en relación directa con otro argumento mediante el que las personas encuestadas describen las posibles diferencias internas en el español de Guinea Ecuatorial: las diferencias ligadas al origen étnico de los hablantes. En su mayoría, se valora mejor el español hablado por los bubis (etnia autóctona de la isla de Bioko) que el español de los fang (etnia predominante en Río Muni) (ver también ejemplo 15 infra: "en lo:s fangs [...] el: espa- el castellano es bastante un poco más / malo que en los bubis", 02_-8HB): 
(5) los fang tienen su manera de hablar el español / los annoboneses / también es que / los la la realidad es que los bubis son los que mejor / hablamos el español [...] [...] [el español de los fang] no es igual al mío es má:s / se escucha más feo se escucha: horroroso [...] lo hablan pero lo hablan mal [...] porque los fang / casi como que nunca les ha importado hablar el español siempre como están en: pueblos son de: de de allí / y siempre hablaban fang (10_+8MB)

Esta diferenciación en el dominio del español se justifica a partir de dos argumentos complementarios, uno sincrónico y otro diacrónico: por un lado, se afirma reiteradamente el hecho de que los fang suelen usar con más frecuencia y en más contextos la lengua fang que los bubis usan el bubi, lo cual conlleva un uso menos fluido del español entre los fang (cfr. Lipski, 2004, p. 118; Schlumpf, 2020a). Por otro lado, se asocia esta diferencia con el proceso de la colonización e hispanización de Guinea Ecuatorial, acorde con lo que afirma Casado-Fresnillo (1995, p. 284): "Siguiendo los pasos de la colonización, el mejor español es el que se habla en la isla de Bioko, tanto por los bubis como por los fang; en el continente, a medida que nos alejamos de la zona costera y nos adentramos en el interior, va empeorando; pero, en general, aunque haya guineanos que no lo hablen, llegan a entenderlo". En efecto, mientras que la colonización española de Bioko se intensificó a partir de 1850, no alcanzó los territorios continentales más alejados de la costa hasta 1930. Esta divergencia entre las diferentes regiones de Guinea Ecuatorial en el proceso de la hispanización y el diverso grado de presencia del español hasta hoy explican que unos castizan mejor que otros. Ahora bien, será fundamental comprobar in situ, mediante una recogida de muestras lingüísticas, si estas diferencias en el dominio del español entre las distintas regiones y etnias se mantienen hasta la actualidad.

La importancia de la educación para adquirir la capacidad de castizar:

(6) los que está:n .h no han ido al colegio: y todo esto / no puede:n castizar como el que ha ido en el colegio (22_+8MF)

(7) a mí no me da igual no quiero que [mis hijos] hablan ese español que habla así: buah no sé qué: no / .h español como de madrileños verdadero es- castella:no / que castizan la gente que saben [...] como enseñan en: en instituto / así / es lo que yo quiero $(22++8 \mathrm{MF})$ 
Recordemos que, tradicionalmente, la escuela representaba - y, en ocasiones, sigue representando hoy en día- el primer contacto entre los guineoecuatorianos y la lengua española. Es allí donde adquieren el idioma de forma institucionalizada y basada en la norma estándar del castellano peninsular septentrional. Pese a que, en la actualidad, hay cada vez más casos de adquisición natural del español en casa como primera o segunda lengua (sobre todo, en zonas urbanas), todavía parecen predominar las lenguas africanas como L1.

d. La asociación de castizar con el español hablado en España, en este caso en Madrid, aunque dejando la opción de que no todos los rasgos del español madrileño son propios de esta manera de hablar (bien) el español:

(8) [en Madrid] también hay gente que castiza:n / pero luego dice cuatro palabras y te: y quinta palabra te mete: dice: palabrota $(22++8 \mathrm{MF})$

Son las palabrotas (o tacos) las que los guineoecuatorianos entrevistados más critican de la variedad madrileña del español. El registro coloquial o vulgar no corresponde a lo que, en su opinión, es castizar la lengua.

e. Finalmente, en un caso se asocia la idea de castizar muy mal con

lo que se denomina guineo, un término despectivo para referirse a la manera guineoecuatoriana de hablar el español (ver más adelante bajo guineo / guíneo, ejemplo 23).

Si nos fijamos en lo que encontramos en diferentes diccionarios de la lengua española, ya hemos señalado que el verbo castizar no está registrado (salvo en el DAmer, pero con otro significado, ver nota 5). En cambio, sí se encuentra el adjetivo correspondiente: castizo / castiza. Analizando las definiciones ofrecidas en varios diccionarios, encontramos algunas de contenido general, pero también otras que se centran en aspectos lingüísticos (y que van resaltadas, a continuación, en negrillas):

1. De buen origen y casta. 2. Típico, genuino del país o del lugar en cuestión. 3. Dicho del lenguaje: Puro y sin mezcla de voces ni giros extraños. 4. En la América colonial, cuarterón 6 . 5. Dicho de un hombre: Muy prolífico (DLE, 2020, s.v. castizo, za).

\footnotetext{
6 "En la América colonial, nacido de mestizo y española, o de español y mestiza" (DLE, 2020, s.v. cuarterón $\left.{ }^{1}, n a\right)$.
} 
1. Que tiene origen conocido y casta. 2. Que es genuino, puro y típico de un determinado lugar: costumbre castiza; tradición castiza; comida castiza. 3. [lenguaje] Que es puro y sin mezcla de elementos extraños a la propia lengua: palabras castizas; babla castiza [...] (DGLE, 2009, s.v. castizo, za).

1. Aplicado al lenguaje, costumbres, tradiciones, rasgos y otras manifestaciones, verdaderamente del país, región, etc., de que se trata y no falseado, espurio, advenedizo o mezclado con cosas ajenas: 'Palabras castizas. Lenguaje castizo. Bailes castizos'. Se aplica al escritor que emplea un lenguaje castizo. Se aplica a la persona que tiene las cualidades que caracterizan a los de la región, profesión, etc., a que pertenece: 'Un aragonés castizo. Un torero castizo' (DUE, 2007, s.v. castizo, za).

Siguiendo estas definiciones, algo castizo (por ejemplo, un uso lingüístico) se relaciona con el origen, lo genuino, lo verdadero (en el caso de nuestros ejemplos, el punto de comparación sería el español peninsular), además de con la pureza, la falta de elementos ajenos (como podrían ser, por ejemplo, elementos de las lenguas de contacto) y la falta de giros extraños (expresiones propias de los hablantes guineoecuatorianos). Sin lugar a dudas, la semántica de castizar, tal como se usa en Guinea Ecuatorial, se basa en estos significados tradicionales de castizo / castiza. Justamente por eso castizar no se asocia, en primer lugar, con el español guineoecuatoriano, sino con una forma (castiza) de hablar el español que se orienta en el modelo peninsular, un modelo que refleja el origen histórico del castellano —además del origen del español en Guinea Ecuatorial-y que constituye, hasta hoy, el punto de comparación y de orientación de los guineoecuatorianos ${ }^{7}$. En definitiva, el uso de castizar, en el sentido de 'hablar (bien) el español', sigue siendo característico del léxico de la variedad guineoecuatoriana del español, tal como ya se señala en estudios clásicos como el de Quilis y Casado-Fresnillo (1995).

\footnotetext{
${ }^{7}$ Ya en tiempos coloniales se difundía la idea de que el español guineoecuatoriano no era un "español castizo". Obsérvese el siguiente testimonio (las cursivas son nuestras): "Nuestros niños hablan la lengua materna o el pichin-inglis en el hogar y en la calle, y sólo se expresan en castellano durante las pocas horas que permanecen en las aulas escolares, por lo que la acción del pensar posee un desdoblamiento: piensa traduciendo, es decir, piensa en su lengua materna y lo traduce al castellano, y esto, evidentemente, es difícil para ejecutarlo simultáneamente. Por ello, habla el español de una manera distinta a la castiza, con un acento especifico" (Castillo Barril, 1966, p. 15).
} 
Por ende, sería imprescindible que, por fin, se reflejara este uso propio de los hablantes guineoecuatorianos en los diccionarios de la lengua española, mediante la incorporación del verbo castizar y una adecuada definición que representara su empleo en el español de Guinea Ecuatorial.

\subsection{INCULCAR}

los españoles / les han inculcao que ellos son mejores (14_-8HF)

Como continuación y complemento del apartado anterior, dedicado a castizar, sigamos con las ocurrencias del verbo inculcar, que aparece 18 veces en 5 de las entrevistas. Enlazando con la importancia de saber castizar en el sentido de 'hablar (bien) el español', aparece en varias ocasiones el verbo inculcar ${ }^{8}$ para subrayar el empeño que varios agentes ponen (o ponían) en que los guineoecuatorianos hablen (hablasen) bien la lengua española. De hecho, aparecen dos de los agentes glotopolíticos que ya hemos conocido en los ejemplos citados anteriormente: los padres y los españoles colonizadores. Los primeros quieren que sus hijos aprendan a hablar bien el castellano, antes de que pongan mucho esfuerzo en dominar su lengua africana (recuérdese también el ejemplo 1 citado arriba):

(9) desde pequeño ya te lo inculcan que tienes que hablar el castellano / y ya después si quieres aprendes tu lengua materna o como tú veas (02_-8HB)

Por otro lado, los colonizadores españoles les han inculcado a los guineoecuatorianos que tienen que hacer las cosas igual que los españoles, así también en materia lingüística. Veamos tres pasajes de una misma entrevista:

(10) y también por la admiración de la gente que te: h que te: que te lo enseña porque: / obviamente: eeeh / en Guinea se ha tenido mucha admiración por los españoles [...] muchísima admiración .h: hemos querido hacer siempre las cosas eeh como lo hacían los españole:s / eeh más que y: y: yo creo que porque también se lo han inculcado así / al: [...] al: al guineano porque también

\footnotetext{
8 "1. Apretar con fuerza algo contra otra cosa. 2. Repetir con empeño muchas veces algo a alguien. 3. Infundir con ahínco en el ánimo de alguien una idea, un concepto, etc. 4. Juntar demasiado unas letras con otras. 5. Afirmarse u obstinarse en lo que se siente o se prefiere" (DLE, 2020, s.v. inculcar).
} 
se lo han inculcado en que .h "nosotros somos mejores eeeh h si hacemos si haces las cosas como las hacemos nosotros entonces eres mejor" (14_-8HF)

(11) los guineanos han hecho las cosas así / porque los españoles / les han inculcao que ellos son mejores // haciendo las cosas o sea .h: en el sentido de que / "si hablas español como yo / pues [...] eres mejor persona eres mejor" (14_-8HF)

(12) por no cuestionar las cosas / eso ha dejado que: hm que en Guinea se hable español exactamente igual que: [...] que aquí en España (14_-8HF)

Este afán de imitar lo español (también podríamos decir lo castizo) se reconoce también en otras entrevistas. Por ejemplo, según una mujer, a los guineoecuatorianos todavía les "queda aprender mucho más del español" (10_+8MB), algo que pueden conseguir, precisamente, aprendiendo de los españoles. La importancia de la época colonial se ve asimismo en la siguiente cita:

(13) ah y una una cosa curiosa / h eh: es: creo que es un poco también por la: / colonización y por 1:a caña que les metieron a: nuestros padres a nuestros abuelos con el / .h "tenéis que hablar español correctamente [...] bla bla bla bla bla".h la gente utiliza un montón de cultismos (07_+8HB)

Según esta persona, el "español correcto" (castizo) se ve reflejado hasta hoy en el español de Guinea Ecuatorial en el uso de cultismos (pone como ejemplo la palabra orate 'loco'). El mismo rasgo se menciona en otras entrevistas, además de la caracterización del español guineoecuatoriano como "español antiguo”. Ambas características del léxico guineoecuatoriano las recogen Quilis y Casado-Fresnillo (1995, pp. 330-331), quienes comentan que "[1]os guineoecuatorianos sienten un atractivo especial por el uso de palabras cultas y raras, en el sentido de pocos $[$ sic] frecuentes. En este aspecto, tiene mucha influencia la enseñanza escolar y los libros de texto, que para la mayoría representan el ideal de corrección y las únicas fuentes para el conocimiento de la lengua española" (Quilis \& Casado-Fresnillo, 1995, p. 330). De nuevo, vemos la asociación de hablar bien el español (castizar) y el empeño en conseguirlo (inculcar) tanto con el ámbito de la educación (escolar y familiar) como también con el proceso de la colonización e hispanización de Guinea Ecuatorial. 


\subsection{DISPARAR Y DISPARATE(S)}

si piensas en un idioma y hablas en otro normalmente disparas .h: ellos dicen / disparates (19_+8HF)

La siguiente pareja de término se usa exclusivamente para hacer referencia al español guineoecuatoriano: el sustantivo disparate(s) y el verbo correspondiente disparar (con 5 ocurrencias en 3 entrevistas y con 2 ocurrencias en 2 entrevistas, respectivamente). Lo que tienen en común todos los usos de disparate(s) y disparar recogidos en las entrevistas es que se trata de términos despectivos que describen ciertos rasgos del español guineoecuatoriano percibidos como erróneos o, al menos, negativos. En una de las entrevistas, se ofrece el término de lapsus como sinónimo de disparate (ver ejemplo 16).

Se deben precisar dos aspectos tomando en consideración los pasajes de las entrevistas en los que aparecen los términos en cuestión:

a. Sobre todo (aunque no solo), se habla de disparar y de disparates en relación con el español hablado por los fang. Recuérdese lo comentado sobre el español de los fang en el apartado dedicado a castizar. Aquí, de nuevo, se establece una diferencia de nivel o cualidad entre el español hablado por los fang y el español hablado por otros grupos étnicos de Guinea Ecuatorial:

(14) a ver los de la isla: ¿vale? se supone que lo hablamos: / mejor y los del continente lo hablan / fatal // todos no estoy segura pero: la gran mayoría lo hablan / muy mal muy mal / hablan como decimos alli disparando [...] en el sent- ojo es / les cuesta mucho pronunciar pero porque: tienen má:s / presente sus lengua vernácula que el: castellano (05_-8MB)

(15) en lo:s fangs [...] el: espa- el castellano es bastante un poco más / malo que en los bubis [...] porque en: plan: / las palabras no las usan: tan bien bien como: / como deben usarlas / dicho: de muy mala manera que / dan: dicen muchos disparates / al hablar a la hora de hablar / [...] cuesta más entenderles (02_-8HB)

Ambos ejemplos subrayan la calidad despectiva de los términos disparar y disparates: en el primero encontramos el comentario atenuador "todos [los del continente] no[,] estoy segura", mientras que en el segundo la persona 
admite que el empleo del término es una "muy mala manera" de designar los fenómenos lingüísticos observados.

b. El concepto de los disparates, según lo recogido en las entrevistas, puede aludir a dos rasgos lingüísticos concretos. El primero de ellos es el uso considerado no adecuado de ciertas palabras o expresiones (02_-8HB, 17_-8MF); y el segundo son los fenómenos resultantes del contacto lingüístico entre el español y las lenguas africanas. Se constata una actitud decididamente negativa frente a estos rasgos derivados del multilingüismo de los guineoecuatorianos (ver también ejemplo 14 supra):

(16) en Guinea / nosotros no hablamos español sino guineo // [...] hablamos guíneo / que es español pff .h: pfff .h: mezclao con: con lo nuestro [...] con algún otro dialecto [...] ¿por qué? porque // como le: comentaba // el que es fang // que sus padres son fa:ng / y demás .h normalmente piensa en fang [...] si piensas en un idioma y hablas en otro normalmente disparas .h: ellos dicen / disparates [...] disparate porque hablas mal // algún lapsus (19_+8HF)

Como muestra este ejemplo, los disparates también son un rasgo típico de lo que se denomina guineo / guíneo, concepto que alude a la forma guineoecuatoriana de hablar el español y que recibe, igualmente, una valoración negativa (ver apartado correspondiente más abajo). Todo ello se puede oponer a las definiciones de castizo y castizar citadas arriba, que, muy por el contrario, describen un español bien hablado, un español 'puro y sin mezcla de voces ni giros extraños'.

Como anécdota, mencionemos que disponemos de una canción de cantantes guineoecuatorianos que caricaturiza la forma guineoecuatoriana de hablar el español mediante el empleo de los términos castizar y disparates. Los disparates hacen alusión, precisamente, a las interferencias con lenguas africanas en el español hablado por los fang. Reproducimos, a continuación, dicho pasaje?:

\footnotetext{
${ }^{9}$ Se trata de nuestra propia transcripción de gran parte de la primera estrofa de la canción mencionada. Disponemos de una versión en audio de la canción, pero desconocemos su título y sus intérpretes. El estribillo de la canción reza como sigue: "No sabemos hablar español, ni sabemos hablar el inglés, ni la segunda lengua, que es el francés, y como tercera lengua nos añaden portugués".
} 
Estoy notando algo, muchos lo podéis notar, que los guineanos todavía no sabemos castizar. Hay palabras en español que pronunciamos mal, por ejemplo, principal, muchos dicen prinsipal.

El famoso verbo que el guineano ha inventado, el verbo hebié, ¿̇de qué libro se ha sacado? Ayer cuando yo iba es cuando le hebié visto, me ha robado dinero, él piensa que es listo.

Los fang, nosotros hablamos más con disparates, por hablar la lengua vernácula en todas partes, mayona, mayona, entre etnias diferentes, $\mathrm{y}$ al intentar castizar, venga a rematar a Cervantes.

Si nos fijamos en las definiciones lexicográficas de disparar y disparate que aluden a hechos lingüísticos, podemos destacar dos matices: por una parte, también se trata de definiciones claramente negativas, pero, por otra, son bastante más imprecisas que las definiciones ofrecidas por las personas encuestadas.

Disparate:

'Hecho o dicho disparatado', 'coloq. barbaridad (\| cantidad grande)' (DLE, 2020, s.v. disparate)

'coloq. atrocidad (I demasía)' (DRAE, 2001, s.v. disparate)

'Objeto o evento mediocre o de mala calidad' (DAmer, 2010, s.v. disparate)

'Cosa, esp. dicho o hecho, absurda o contraria a la razón', 'Palabra malsonante' (DEA, 2011, s.v. disparate)

'Dicho o hecho totalmente absurdo, equivocado o carente de lógica o sentido' (DGLE, 2009, s.v. disparate)

'Cosa absurda, falsa, increíble o sin sentido que se dice por equivocación, ignorancia, trastorno de la mente, etc.', 'Maldición, insulto violento, palabrota o terno' (DUE, 2007, s.v. disparate)

'Hecho ù dicho fuera de propósito y de razón' (Autoridades, 1963 [1726-1737], s.v. disparate)

\section{Disparar(se):}

'Hablar u obrar con extraordinaria violencia y, por lo común, sin razón' (DLE, 2020, s.v. disparar)

'Expresar alguien incoherencias, a causa del enojo u otra razón, sin pensar en lo que se dice', 'Salirse del tema que se está tratando o hablando' (DAmer, 2010, s.v. disparar[se]

'Lanzar [un golpe, o una acometida verbal]' (DEA, 2011, s.v. disparar)

'Decir o hacer disparates' (DUE, 2007, s.v. disparar) 
Asimismo, resulta interesante consultar el verbo disparatar, aunque esta forma no aparece en nuestras entrevistas:

'Decir o hacer algo fuera de razón y regla' (DLE, 2020, s.v. disparatar)

'Decir disparates' (DEA, 2011; DUE, 2007, s.v. disparatar)

'Decir o hacer disparates' (DGLE, 2009, s.v. disparatar)

'Decir ò hacer alguna cosa fuera de propósito y de razón' (Autoridades, 1963 [1726-1737], s.v. disparatar)

En el DAmer (2010), disparatar no aparece, sino que se remite al verbo disparatear (que, a su vez, no está registrado en el DLE, 2020):

'Decir palabras groseras', 'Expresar conceptos sin fundamento, especialmente en una conversación' (DAmer, 2010, s.v. disparatear)

Si bien las definiciones recogidas en los diccionarios reflejan la actitud negativa que los guineoecuatorianos expresan frente a los disparates, no encontramos las interpretaciones concretas que observamos en las entrevistas. Sí vemos reflejada la idea de las "palabras mal usadas" en definiciones como 'hecho o dicho disparatado' (DLE, 2020, s.v. disparate), 'expresar alguien incoherencias' (DAmer, 2010, s.v. disparar) o 'decir [...] algo fuera de razón y regla' (DLE, 2020, s.v. disparatar). Por el contrario, la alusión a los fenómenos lingüísticos que resultan del contacto del español con otras lenguas, especialmente en el habla de los fang, no aparece en las definiciones lexicográficas. Concluimos, por lo tanto, que estamos ante otro guineanismo léxico, no comentado hasta ahora, que entraría en la categoría de las ampliaciones semánticas y que permitiría añadir una nueva acepción a las definiciones lexicográficas existentes.

\subsection{GUINEO / GUIINEO}

en Guinea / nosotros no hablamos español sino guíneo (19_+8HF)

En el apartado precedente hemos comentado las alusiones a los disparates, que, según algunos entrevistados, pueden darse en la variedad guineoecuatoriana del español y describen ciertas desviaciones frente al castellano peninsular; este último, por contraposición, se podría denominar español castizo. 
Un término más global que sirve para describir el español guineoecuatoriano en su conjunto es guineo / guíneo. Aunque solo lo usan dos de las personas entrevistadas, podemos afirmar que es, en efecto, un concepto con cierto uso en Guinea Ecuatorial, como veremos más adelante.

Uno de los fragmentos en los que aparece guíneo lo hemos reproducido anteriormente, un pasaje en el que se define el guíneo mediante el uso de los llamados disparates (o lapsus) (ver ejemplo 16 supra). En otra entrevista encontramos varias facetas adicionales del guineo, que se pueden resumir como sigue:

a. El guineo como una variedad poco prestigiosa de la lengua española, como un español mal hablado:

(17) el español que hablamos / es un poco raro / es un poco feo como te he dicho entonces ellos mismos vulgarmente .h: lo: lo apodaron el guineo (13_-8HF)

(18) en mi país hablamos mucho más el guineo / el: castellano mal hablao el español mal hablao (13_-8HF)

(19) si vuelvo a ir / si vuelvo a Guinea ahora: llevo dos años .h hay probabilidad que empiece a hablar mal el el el español ¿sabes? y: / automáticamente estaré hablando el guineo [...] porque: todos los días encontrar a gente que hablan mal el e- ca- el castellano (13_-8HF)

b. La importancia de los estudios para llegar a un buen nivel del castellano:

(20) realmente / no hablamos muy bien el castellano [...] si llego si no llegas / a un buen nivel de estudios en mi país / no: no puedes llegar a hablar bien: / muy bien el castellano (13_-8HF)

(21) y: lo más importante de todo esto es que / el español más habl- ma- mal hablado / .h entonces la gente como te he dicho antes / gente que no han llegado a un buen nivel de estudios / .h hablan muy mal el guineo (13_-8HF)

(22) para que lo hables bien cuando vas creciendo y vas a clase / hay que: [...] dar mucho esfuerzo [...] hay que leer mucho (13_-8HF)

Según el joven guineoecuatoriano citado, un ejemplo concreto que caracteriza el guineo es un mal uso de los verbos:

(23) una de las cosas que te puedo decir del: eh del guineo hm de: español mal hablado es: / eeh habla:r / sin: basarse en los verbos / el castellano es muy mejor .h cuando lo hablas / en verbos [...] y cuando no lo hablas en verbo / es que lo estás hablando mal [...] ¿sabes? / estás castizando muy mal [...] y: esta forma de castizar es la que: en mi país se llama vulgarmente hablamos el guineo (13_-8HF) 
Ofrece dos ejemplos concretos de este "español mal hablado": decir voy a casa en vez de me voy a casa, y decir esta canción tarda (esta última expresión la considera mal usada y formula la siguiente pregunta retórica al respecto: “¿cómo que una canción no va a tardar?”).

d. En Madrid, la gente no habla guineo (sino que castiza), de modo que uno tiene que cambiar su forma de hablar el español cuando llega desde Guinea Ecuatorial:

(24) no tienes que volver a hablar el guineo aquí [en Madrid] porque: / ya no: estás con la gente con quien hablabas el guineo (13_-8HF)

e. Según este mismo entrevistado, la culpa de la existencia del guineo en Guinea Ecuatorial la tienen los colonizadores españoles (con esto contradice, hasta cierto punto, lo que hemos visto en ejemplos anteriores en relación con castizar e inculcar):

(25) [los españoles] no dieron el empeño de: formar a la gente para que la gente sepan hablar el: castellano (13_-8HF)

Es por esto que "los guineanos quedaron // con un mal castellano".

Particularmente interesante resulta la comparación que establece esta misma persona entre la oposición guineo ('español mal hablado en Guinea Ecuatorial') frente a castellano ('español castizo') y la oposición pichi ${ }^{10}$ ('inglés mal hablado en Guinea Ecuatorial') frente a inglés ('inglés verdadero'). Esta comparación refleja perfectamente lo visto en relación con la supuesta "pureza" de las normas estándares europeas (castellano e inglés, en este caso) frente a variantes más periféricas (excéntricas) de las mismas lenguas, surgidas en contextos coloniales en el seno de sociedades plurilingües y multiculturales. En relación con el pichi, además, se emplea otro verbo despectivo que, parecido

\footnotetext{
${ }^{10}$ El pichi es un pidgin de base inglesa con amplia difusión en la isla de Bioko, especialmente en Malabo. Sirve de lingua franca entre representantes de distintos grupos étnicos y, además, permite la comunicación con personas de otros países africanos tales como Nigeria, Camerún, Ghana o Sierra Leona. Como acercamiento al pichi se pueden consultar la introducción a la Gramática del pichi (Yakpo, 2010, pp. 9-19) y otras publicaciones del mismo autor (por ejemplo, Yakpo, 2013, 2016).
} 
a disparar, refleja la actitud negativa frente a este código lingüístico: chapurrear $^{11}$. Se trata del siguiente ejemplo: "en la calle / así entre jóvenes el: pichinglish / que es una especie de inglés chapurreado así: muy mal chapurreado pero: / sí: / para entre los jóvenes para entendernos" (02_-8HB). En general, la valoración del pichi es mayoritariamente negativa, pese a que también se reconoce su función de lingua franca (entre distintas etnias de Guinea Ecuatorial y para la comunicación con los nigerianos) o como código intra-grupal de los jóvenes. Entre las descripciones negativas del pichi aparecen las siguientes: es "algo cutre", no es "correcto", es un idioma asociado a "delincuencia", "una lengua para bandidos", "no es inglés ni es nada", es el "inglés Brooklyn", el "broken English", el "inglés africano", "una especie de inglés mal hablado", una "réplica" del inglés, un "inglés pero muy barato". El verbo chapurrear también aparece una vez en relación con el español guineoecuatoriano, cuando alguien habla de los guineoecuatorianos que nacen y crecen en España: "aunque en casa / tenga: / por ejemplo: tenga un padre que: / lo chapurrea un poco mal o algo así / pero: al estar en un ambiente todo el día: / en plan que lo se lo hablan bien / yo considero que va: va a hablar bien" (02_-8HB). En conformidad con el punto d., aquí el español chapurreado de ciertos guineoecuatorianos se opone al español castizo hablado en Madrid.

Recordemos, asimismo, un pasaje clave del ejemplo 16 citado arriba: "en Guinea / nosotros no hablamos español sino guíneo // [...] hablamos guíneo / que es español pff .h: pfff .h: mezclao con: con lo nuestro [...] con algún otro dialecto" (19_+8HF). Incluso la entonación y la expresión no verbal $p f f$ subrayan la actitud negativa frente al guíneo en su conjunto y, en particular, frente a las interferencias lingüísticas de las lenguas africanas (los disparates). Desde un punto de vista conceptual y terminológico, queremos

11 'Hablar una lengua con dificultad y cometiendo errores' (DLE, 2020, s.v. chapurrear); 'Chapurrear un idioma' (DAmer, 2010, s.v. chaporrear). 
resaltar, además, el hecho de que las lenguas africanas no se describen como lenguas, sino como dialectos, aspecto que retomaremos en las reflexiones teórico-ideológicas.

Ya hemos señalado que la expresión guineo para hacer referencia al español guineoecuatoriano tiene cierta difusión en Guinea Ecuatorial. Un caso representativo es el folleto ilustrado Hablamos guineo ${ }^{12}$, elaborado por Locos por Cultura ${ }^{13}$, una red de jóvenes artistas guineoecuatorianos con representación en las ciudades de Malabo y Bata. Las ilustraciones, realizadas en la Escuela de Dibujo EG Pencil de Locos por Cultura, representan escenas cotidianas ubicadas en diferentes barrios de Malabo y las conversaciones reflejan rasgos considerados típicos del habla guineoecuatoriana. Se comenta de forma explícita el concepto de guineo (ilustración 1); aparecen expresiones típicamente guineanas como mainn o kieh / akeh (ilustraciones 1-3); y se reproducen ejemplos que representan lo que la persona citada anteriormente (13_-8HF) describiría como un uso inapropiado de los verbos: "vengo voy un poco en el baño" (ilustración 4) y "salte fuera [bajo la lluvia]" (ilustración 5). Algunos de estos fenómenos lingüísticos se destacan también en nuestro corpus de entrevistas como rasgos característicos del español guineoecuatoriano, por ejemplo, las expresiones [chico] main 'no estoy de acuerdo, paso' (02_-8HB) y ikieh! / jakiéb! (expresión onomatopéyica de sorpresa tomada del fang) (07_+8HB), la construcción del verbo ir + preposición en + indicación del destino (por ejemplo, 06_-8MB) ${ }^{14}$ o el uso de salte [de mi casa] 'vete' (02_-8HB).

\footnotetext{
${ }^{12}$ Le expresamos nuestro agradecimiento a Cristian Eteo Botau, quien nos facilitó una versión digital de Hablamos guineo y nos dio el permiso de reproducir algunos ejemplos e ilustraciones en este trabajo.

${ }^{13}$ Como leemos en su cuenta en Twitter: "Locos por Cultura (LPC) es una red de comunidades de jóvenes artistas de Guinea Ecuatorial, que usan el arte para transformar sus comunicades $[\mathrm{sic}]$ y sus vidas" (https://twitter.com/locosporcultura, fecha de consulta: 12.2.2021).

${ }^{14}$ Ofrecemos una síntesis del empleo en todo el corpus de entrevistas de las combinaciones $i r+$ preposición en / $a+$ indicación de destino en Schlumpf (en prensa a).
} 


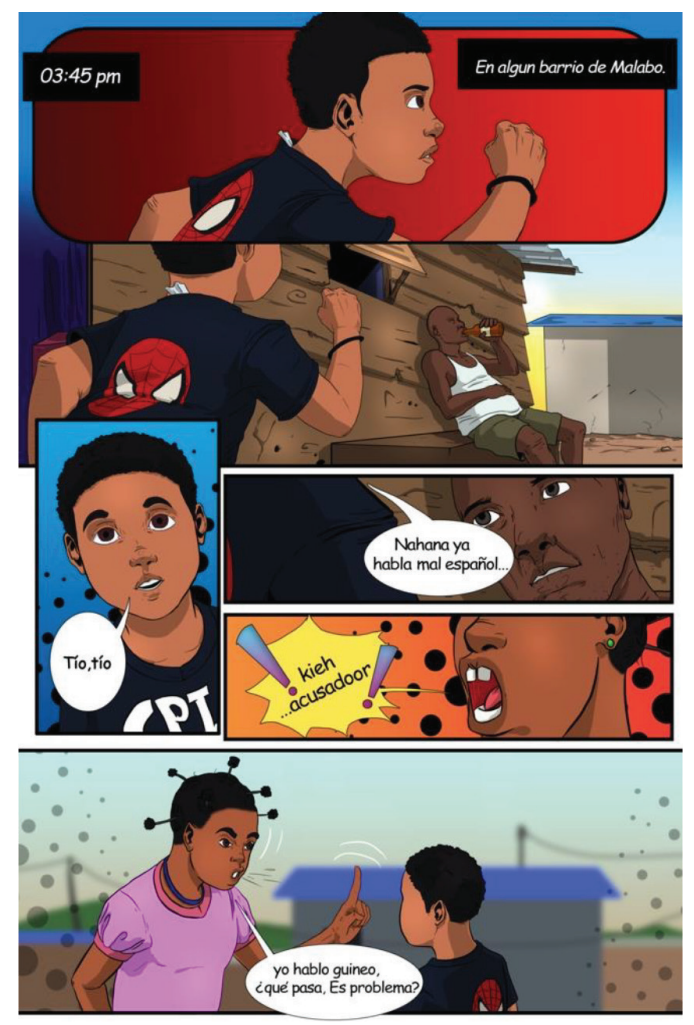

ILUSTRACIÓN 1: Locos por Cultura: Hablamos guineo (pág. O)
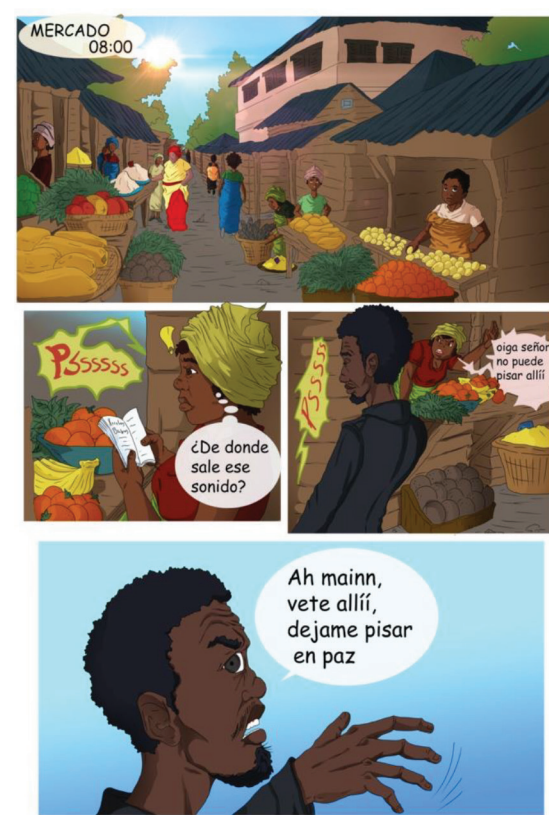

ILUSTRACIÓN 2: Locos por Cultura: Hablamos guineo (pág. 10)15

${ }^{15}$ El verbo pisar 'mear' es tomado, probablemente, del pichi / inglés (piss) o del francés (pisser). 

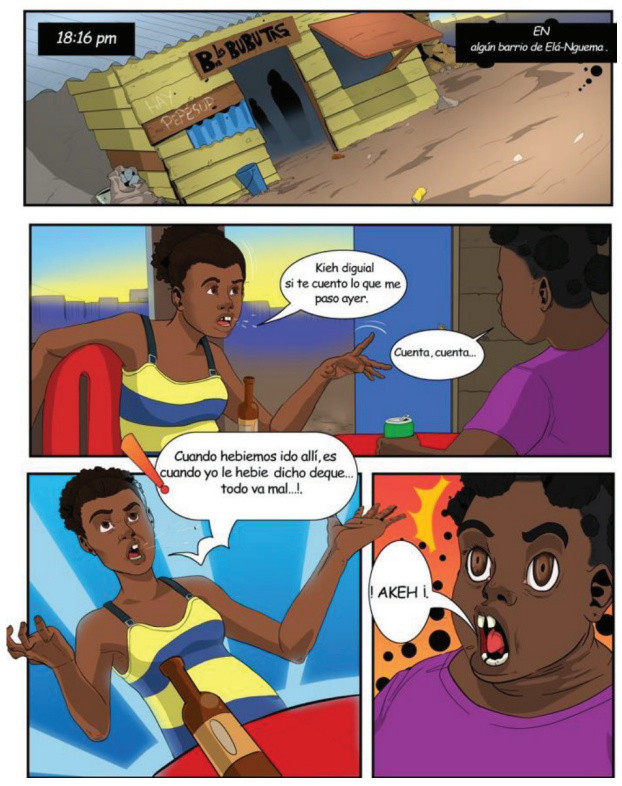

Ilustración 3: Locos por Cultura: Hablamos guineo (pág. 2) $)^{16}$

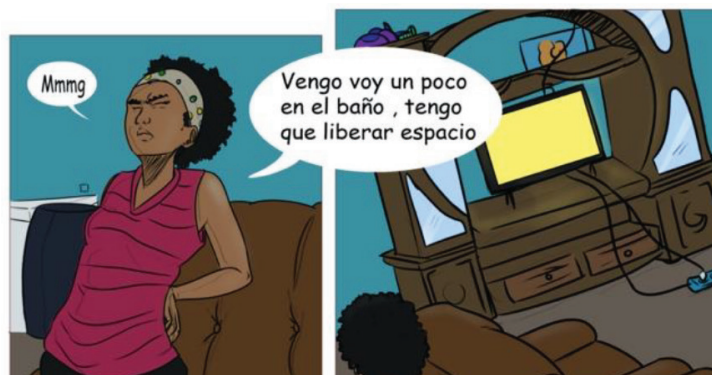

ILUSTRACIÓN 4: Locos por Cultura: Hablamos guineo (viñetas tomadas de la pág. 4)

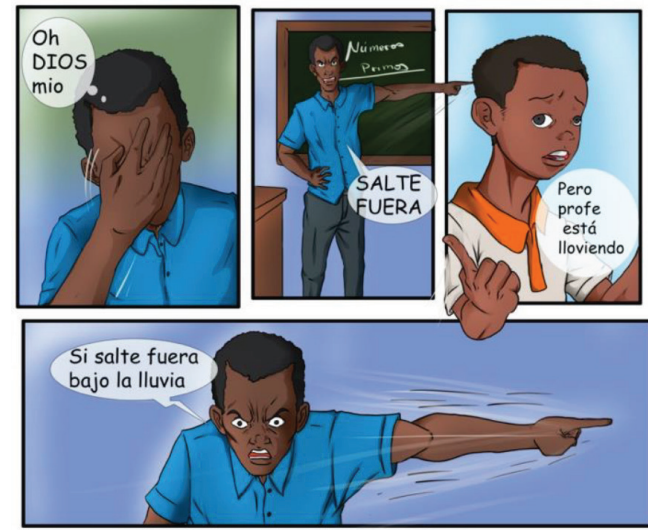

ILUSTRACIÓN 5: Locos por Cultura: Hablamos guineo (viñetas tomadas de la pág. 11) 17

${ }^{16}$ Esta forma del verbo auxiliar haber para construir los tiempos compuestos (bebiemos ido, hebie dicho) asimismo aparece en la canción citada arriba (le bebié visto).

${ }^{17}$ Otro ejemplo del mismo tipo se cita en una de nuestras entrevistas para ejemplificar los lapsus que caracterizan el guineo / guíneo: "oye, Javi, voy a bajar un momento abajo" (19_+8HF). 
Si leemos la definición de guineo en el DLE (2020), vemos que no aparecen acepciones relacionadas con el habla de los guineoecuatorianos:

1. adj. guineano. 2. m. Cierto baile de movimientos violentos y gestos cómicos, que era propio de la gente de raza negra. 3. m. Tañido o son del guineo, que se toca en la guitarra. 4. m. plátano guineo. 5. f. Moneda inglesa de oro de Guinea, que se pagaba a 21 chelines, en lugar de los 20 de una libra normal. Se usaba como unidad monetaria para ciertos géneros (DLE, 2020, s.v. guineo).

La primera acepción sí alude a Guinea Ecuatorial, remitiendo a la entrada del adjetivo guineano, donde hallamos dos acepciones relacionadas con este país:

[...] 3. Natural de la Guinea Ecuatorial, país de África. 4. Perteneciente o relativo a Guinea, a Guinea-Bisáu, a Guinea Ecuatorial, o a los guineanos (DLE, 2020, s.v. guineano, na).

Las acepciones 2 y 3 que aparecen bajo guineo describen realidades relacionadas con África: un "baile de movimientos violentos y gestos cómicos, que era propio de la gente de raza negra" y el "[t]añido o son del guineo, que se toca en la guitarra". Ambos conceptos conllevan un claro tono despectivo frente a las personas de piel negra. El último mencionado es de especial interés en el contexto de este trabajo, ya que alude a una realidad lingüística:

Los Guineos, Negros o Negrillas (también llamados "villancico de negros"), eran un género de villancicos que pretendían retratar a los esclavos africanos, imitando su música y su manera de hablar. Cuando un villancico daba voz a personajes africanos que hablaban en una temprana variedad criolla del castellano o el portugués, a veces mezclando algunas palabras sueltas de la lenguas yoruba o bantú, se denominaban normalmente negro, negrilla o guineo, y tendía a incorporar los fuertes esquemas rítmicos de percusión que eran considerados típicos de las danzas africanas, así como efectos antifonales y de responso entre los solistas y el "tutti", que eran frecuentemente asociados con las ejecuciones vocales de la tradición africana. ${ }^{18}$

La cuarta acepción que ofrece el DLE (2020) es, quizás, la más conocida y aparece, asimismo, en el DAmer (2010, s.v. guineo): el guineo como tipo de plátano. Vemos, pues, que la única definición relacionada con un contenido

\footnotetext{
${ }^{18}$ MusicaAntigua (2017). Guineos, Negros, Negrillas o Villancicos de Negros. http://www. musicaantigua.com/guineos-negros-negrillas-o-villancico-de-negros/?utm content=buffer $5794 \mathrm{c} \& u t m$ medium=social\&utm source=plus.google.com\&utm campaign=buffer [fecha de consulta: 22.02.2021].
} 
lingüístico es la acepción 3; sin embargo, no se refiere ni únicamente a Guinea Ecuatorial — sino a la manera (estereotipada) de los esclavos africanos de hablar el español o el portugués - ni a una realidad presente — sino a una época histórica pasada-. Lo que observamos aquí es un tipo de precursor más general del concepto de guineo que encontramos en la Guinea Ecuatorial contemporánea, que todavía no alude a una variedad específica del español, pero que ya contiene el toque despectivo que también vemos reflejado en los ejemplos de nuestras entrevistas. Reconocemos dos puntos problemáticos con respecto a las definiciones lexicográficas de guineo: por un lado, las definiciones recogidas en el DLE siguen transmitiendo una postura negativa (por no decir racista) frente a realidades africanas (no ayuda mucho que se trate de realidades pasadas). Este problema es comparable al que se viene criticando, por ejemplo, con respecto a entradas o definiciones sexistas que siguen apareciendo en el diccionario académico (cfr. Bengoechea, 2001; Forgas, 2011; Vargas et al., 1998). Por otro lado, tenemos aquí otro ejemplo que nos demuestra que la realidad de la lengua española en Guinea Ecuatorial está mínimamente representada en el DLE (2020). Sin duda, merecería la pena revisar y actualizar las definiciones de guineo, teniendo en cuenta el uso del término para hacer referencia a la variedad guineoecuatoriana del español. Al mismo tiempo, sería recomendable que, desde la dialectología, se revisaran las interpretaciones y descripciones negativas frente al español guineoecuatoriano para promover una visión más neutral frente a las características propias de esta variedad, lo cual quizás hiciera posible, en el futuro, que también los propios guineoecuatorianos tuvieran una actitud más positiva frente a su manera de hablar el español.

\section{REFLEXIONES 'TEÓRICO-IDEOLÓGICAS}

En esta segunda parte de la contribución vamos a plantear cuatro reflexiones teórico-ideológicas a modo de interpretación del estudio léxico-semántico precedente. 
En primer lugar, situemos este trabajo en su contexto postcolonial. Cuando comparamos el español hablado en España (modelo del habla castiza) con el español hablado en Guinea Ecuatorial (el guineo), oponemos dos variedades muy diferentes entre sí por su historia, configuración sociolingüística y posición ideológica en el mundo hispanohablante. Mientras que el castellano peninsular sirve de modelo (o norma) y se concibe como variedad estándar (céntrica), el español guineoecuatoriano es una variedad claramente periférica (excéntrica), tanto geográfica como ideológicamente, no reconocida como variedad propia del español, que ha surgido en un contexto colonial. Más en concreto, el trasfondo colonial ha aparecido de dos maneras en este estudio: por un lado, en forma de comentarios que aluden al proceso de hispanización y colonización de Guinea Ecuatorial. Dos aspectos destacan particularmente: hay guineoecuatorianos que les echan la culpa a los españoles de que en Guinea Ecuatorial no hablen bien el español ("los españoles no nos formaron tanto", 13_-8HF). La idea de que los guineoecuatorianos "no sabemos castizar" aparece tanto en las entrevistas como en la canción citada. Asimismo, la actitud de los colonizadores españoles tiene como consecuencia que los guineoecuatorianos piensan que tienen la necesidad de imitarlos, así también su forma de hablar el español: "los españoles / les han inculcao que ellos son mejores" (14_-8HF). Ambas ideas establecen una jerarquía entre lo español (como algo superior o mejor) y lo guineano (como algo inferior o peor). Por otro lado, el contexto de la colonización se menciona en relación con las diferencias internas en Guinea Ecuatorial por lo que concierne al dominio de la lengua española, especialmente entre la isla de Bioko (asociada a la etnia de los bubis) y la parte continental (asociada a los fang). Las diferentes fases de la hispanización explican, desde una perspectiva diacrónica, la mayor presencia del español en Bioko que en Río Muni. Esta situación persiste hasta el día de hoy e implica una frecuencia de uso más amplia del fang en el continente que del bubi en Bioko. Este argumento sirve para explicar las diferentes formas de hablar el español: los guineoecuatorianos en 
la isla castizan mejor que los fang del interior; estos últimos muestran más cambio de código (disparates) y, por lo tanto, castizan peor.

En segundo lugar, echemos una mirada a la situación sociolingüística del español en Guinea Ecuatorial. Resulta de especial interés recordar que, para muchos guineoecuatorianos, el español no es su única lengua (de hecho, todas las personas entrevistadas son bilingües o trilingües) ni, en muchos casos, su primera lengua. La sociedad guineoecuatoriana se caracteriza por la coexistencia de diferentes idiomas, situación que se refleja en los repertorios dinámicos de sus habitantes con variadas muestras de multilingüismo. Dentro de la variedad de lenguas que coexisten en el país —especialmente, las lenguas africanas de la familia de las lenguas bantúes, las dos lenguas de contacto: pichi y fá d'ambô, así como varias lenguas románicas-, se observan grandes diferencias por lo que respecta a su difusión, estatus oficial, reconocimiento y prestigio. El español es la primera lengua oficial, predomina en todos los contextos públicos, sirve de lingua franca en toda la población y goza de actitudes generalmente positivas entre los guineoecuatorianos. Asimismo, tienen estatus cooficial el francés y el portugués (desde 1998 y 2011, respectivamente). Las demás lenguas no tienen ningún reconocimiento oficial ni se usan apenas en los medios de comunicación ni mucho menos en la enseñanza, ámbito dominado por el español. Ante este trasfondo, se entienden perfectamente dos temas que aparecen en nuestras entrevistas: la importancia de una buena educación y el rol principal del español como lengua oficial. En cuanto al primer aspecto, recordemos que existe la opinión de que un buen dominio del español (saber castizar) se adquiere, precisamente, en un contexto escolar, más que en la calle o en el ámbito familiar. Quien tiene un buen nivel de estudios, alcanza con más probabilidad un buen nivel del español. Este español castizo se orienta en un modelo peninsular centro-septentrional, que coincide con el modelo predominante que representaban los españoles que estaban presentes en Guinea Ecuatorial durante la época colonial: la mayoría de misioneros, funcionarios, comerciantes y 
terratenientes pertenecían a las clases sociales medias y provenían de las ciudades de Madrid y Valencia, así como de Cataluña y Aragón (cfr. Lipski, 1986, pp. 122-123 y 216; 2002, p. 83; 2004, p. 124). La importancia de adquirir un buen dominio del español viene reforzada por el hecho de que actualmente se trata de la primera lengua oficial del país: mientras que, en tiempos coloniales, los españoles les inculcaron a los guineoecuatorianos que deberían aprender el español, hoy esta presión la ejercen ciertos padres frente a sus hijos. Este fenómeno ya lo comenta Lipski (2004, p. 118):

Many Guineans speak Spanish spontaneously (and even exclusively) in their homes, often encouraging their children to speak Spanish in preference to indigenous languages or pidgin English, but according to my extensive observations, which include considerable personal contact with Equatorial Guinean households, the reality is somehow different, with Spanish being freely mixed with the native languages of the respective speakers.

Tal como lo advierte este autor, la realidad sociolingüística en Guinea Ecuatorial es enormemente compleja y abarca un gran continuo de constelaciones lingüísticas. No obstante, sin dudas, el empeño en conseguir que los hijos aprendan a hablar bien el español (que aprendan a castizar) va en detrimento de las lenguas africanas, cuya transmisión puede verse afectada, especialmente entre las etnias minoritarias del país (o sea, las etnias diferentes a los fang).

En tercer lugar, recordemos los conceptos de guineo y disparates, ambos valorados negativamente por las personas entrevistadas. El primer término se refiere a la variante guineoecuatoriana de hablar el español, que incluye expresiones típicas (por ejemplo, préstamos de las lenguas africanas) y usos propios (por ejemplo, en el empleo de los verbos), tal como se refleja, asimismo, en el folleto Hablamos guineo publicado por Locos por Cultura. Los disparates, por su parte, aluden a ciertos rasgos de esta misma variedad del español, tales como usos propios (considerados inadecuados) de ciertas palabras o interferencias lingüísticas (calificadas negativamente). Con cierta frecuencia, los rasgos citados se relacionan de modo específico con el español hablado por los fang, el grupo étnico mayoritario de Guinea Ecuatorial, 
autóctono de la región continental. Hemos visto que también la canción citada destaca que son los fang quienes hablan un español lleno de disparates "por hablar la lengua vernácula en todas partes". Estos disparates y demás particularidades del español guineoecuatoriano van en contra de la imagen idealizada de un español castizo, libre de elementos extraños (no castizos). En uno y otro caso — guineo y disparates-, predominan valoraciones claramente negativas: se trata del "castellano mal hablao el español mal hablao", un español "un poco raro", "un poco feo" (13_-8HF). En esta línea de argumentación, el guineo se compara con el pichi, considerado una desviación del inglés "verdadero":

(26) en la calle / así entre jóvenes el: pichinglish / que es una especie de inglés chapurreado así: muy mal chapurreado pero: / sí: / para entre los jóvenes para entendernos (02_-8HB)

(27) una especie de inglés / mal hablado bueno de [...] inglés africano (01_-8HB)

(28) es una réplica [...] por decirlo así del inglés pero muy barato o sea: [...] no es inglés ni es nada es una // a lo mejor algo que suena inglés (05_-8MB)

(29) el broken English [...] el inglés mal hablado / generalmente: de origen: nigeriano / que se habla también en Guinea (19_+8HF)

Estas descripciones negativas del pichi, siempre en oposición al inglés, asimismo se pueden aplicar al guineo, en oposición al español. Tales actitudes negativas frente a variedades no estándares de lenguas europeas se pueden poner en relación con los múltiples testimonios tempranos, recogidos por John Lipski (2007, pp. 80-84 y 2014, pp. 866-873), que describen el español hablado por los guineoecuatorianos de manera despectiva como un español incorrecto y mal hablado. En particular, se critica reiteradamente el perfil multilingüe de los guineoecuatorianos y sus posibles consecuencias en el habla. Por citar un ejemplo, Manuel Castillo Barril (1966, p. 10) habla del "problema particularísimo del bilingüismo" y explica que "el bilingüismo, y, por analogía, el polilingüismo, es uno de los problemas más acuciantes y complejos [...] no sólo por sus efectos psicológicos, sino por los políticos y sociales que implican". Por desgracia, el estereotipo del español mal hablado de los guineoecuatorianos se ha mantenido, al menos en partes, hasta hoy. 
En muchas ocasiones, tiene consecuencias negativas para el estudio científico del español de Guinea Ecuatorial porque imposibilita un acercamiento libre de prejuicios. Adicionalmente, esta imagen del español guineoecuatoriano puede influir de modo negativo en la actitud de los propios hablantes frente a su variedad del español.

En relación con el guineo y los disparates, asimismo nos parece relevante recordar el hecho de que las lenguas africanas no se clasifican como lenguas, sino como dialectos. Esta elección terminológica es de gran relevancia, dado que subraya aún más el carácter negativo de las interferencias entre dichas lenguas y el español: en los hablantes guineoecuatorianos del español no solo se dan interferencias lingüísticas (valoradas negativamente por dañar la "pureza" del idioma), sino que estas últimas proceden, ni siquiera, de otras lenguas (por ejemplo, lenguas oficiales o estandarizadas), sino de dialectos africanos. De hecho, el ejemplo 16 citado arriba es representativo para lo que podemos observar en todo el corpus de entrevistas, a saber, una tendencia bastante clara en el uso de los conceptos lingüísticos lengua, idioma y dialecto. La tabla 2 muestra su distribución cuantitativa en las entrevistas.

\begin{tabular}{|l|c|c|}
\hline \multicolumn{1}{|c|}{ Conceptos analizados } & $\begin{array}{c}\text { Ocurrencias en las entre- } \\
\text { vistas }\end{array}$ & $\begin{array}{c}\text { Referencias a lenguas } \\
\text { africanas }\end{array}$ \\
\hline lengua (sust.) & 131 & 55 \\
\hline idioma (sust.) & 68 & 13 \\
\hline dialecto (sust.) & 33 & 26 \\
\hline
\end{tabular}

TABLA 2: Conceptos lingüísticos analizados con número de ocurrencias y referencias a lenguas africanas

En cuanto al empleo de lengua, idioma y dialecto en las entrevistas, podemos resumir las siguientes tendencias y sus implicaciones teórico-ideológicas:

a. Del término lengua aparecen 131 ocurrencias, de las que 55 remiten a lenguas africanas y 29 al español, mientras que el resto hace referencia a otras lenguas o al concepto lengua en general. Si nos fijamos en las ocurrencias relacionadas con las lenguas africanas, vemos que predominan sus valores culturales e identitarios (frente al español 
como lengua oficial): lengua materna (14 ocurrencias), lengua local (2), lengua vernácula (2). Solo dos veces se emplea la combinación lengua oficial para hablar de las lenguas africanas (combinación más frecuente en el caso del español), aunque entonces se subraya, precisamente, que el fang no es lengua oficial en Guinea Ecuatorial, pero que debería serlo. Además, son recurrentes las combinaciones con determinantes posesivos, subrayando de nuevo la importancia para la identidad de los hablantes: mi lengua, tu lengua, nuestras lenguas; o los grupos étnicos con sus lenguas propias. El fang, además, es lengua mayoritaria de Guinea Ecuatorial.

b. El término idioma aparece 68 veces, 13 de las ocurrencias haciendo referencia a las lenguas africanas, 25 al español, y el resto a otras lenguas o a idioma en general. Cuando hace referencia a las lenguas africanas, predominan aspectos negativos: los fang siempre hablan su idioma y no les interesa hablar español; el fang es un idioma secundario frente al español; en el español de Guinea Ecuatorial se dan frecuentes interferencias (valoradas negativamente) de los idiomas locales; en Guinea Ecuatorial hay muchos idiomas, por tanto, es mejor hablar español (lingua franca); y la dificultad de transmitir las lenguas africanas implica que ya no hablas tu idioma.

El término dialecto, finalmente, se emplea 33 veces; la gran mayoría de las ocurrencias (26) se refiere a lenguas africanas, mientras que el resto son referencias poco claras o alusiones a diferentes dialectos de una lengua concreta. De nuevo, destacan las combinaciones sintácticas con posesivos: mi dialecto, su dialecto, nuestro dialecto; y se emplea una sola vez la expresión el dialecto de casa.

De especial interés son los pasajes de las entrevistas en los que se establece una oposición terminológica clara y directa entre dos de los términos tratados, en especial, lengua o idioma frente a dialecto. Tales ejemplos muestran 
y, al mismo tiempo, refuerzan jerarquías lingüísticas, en estos casos siempre entre lenguas europeas, por un lado, y dialectos africanos, por otro:

(30) tienen también su dialecto también es como yo es que en Guinea hay mucho dialecto hablamos el dialecto / pichi como te he dicho [...] como si fuera inglés pero no es inglés [...] lo mezclan así [...] entonces hablamos fang hay kombe bubi .h bisió que habla:n / dialecto / y español [...] porque español es la lengua oficial // de Guinea Ecuatorial (22_+8MF)

(31) él sí habla mucho el diale- habla: lenguas habla francés / él habla francés muy bien .h: ya e:- por e- el angoleño:s hablan fran- [...] portugués [...] y luego tienen dialecto como yo $(22++8 \mathrm{MF})$

(32) si se va hablando del vasco el catalán y otras lenguas / o sea me p- ya creo que ya: es / cómo se dice / como nosotros tenemos nuestro dialecto el fa:ng y así (15_-8HF)

Recordemos que no es poco frecuente que el concepto de dialecto se asocie con un estatus lingüístico inferior o marginal frente al concepto de lengua. En el caso de las lenguas europeas, muchas veces se describen como dialectos las variedades rurales o periféricas, entendidas como inferiores frente a otras variantes de la misma lengua; en los contextos coloniales, en cambio, suelen ser las lenguas de los pueblos conquistados las que se asocian con esta etiqueta. En tales casos, la diferenciación entre lengua y dialecto sirve para destacar (y justificar) la superioridad de los conquistadores, de su lengua y su llamada "civilización", frente al estado "salvaje" y "primitivo" de las llamadas "tribus" autóctonas, sus culturas y sus lenguas (cfr. Calvet, 2005, pp. 68-69 y p. 98; Creus, 2007, p. 41; Woolard \& Schieffelin, 1994, p. 63). No pocas veces esta situación conllevó la muerte de dichas lenguas frente a la imposición absoluta de la lengua europea, proceso conocido como glotofagia en la terminología acuñada por Louis-Jean Calvet (vid., por ejemplo, Calvet, 2005). Las lenguas colonizadas quedaban relegadas al ámbito cerrado de la familia y, por lo general, no podían asumir funciones oficiales. En el caso de África, esta situación se mantiene hasta hoy: en la gran mayoría de los países, solo lenguas europeas son oficiales, situación que una y otra vez corrobora la dicotomía reflejada en la oposición conceptual y terminológica entre lengua y dialecto (cfr. Creus, 
2007, p. 51). Nos parece adecuado añadir aquí una cita de Zimmermann (2004, pp. 31-32), pese a que este autor se refiere a la situación lingüística en México:

Más bien hay que admitir que la sociedad hispanófona de México viene aplicando y
sigue aplicando una serie de estrategias - conscientes e inconscientes, coordinadas
e incoordinadas, a nivel macrosocial e interpersonal - que sugieren a la población
indígena en general que ella tiene menor valor y que sus lenguas, que son símbolos
por excelencia de su cultura, son por un lado deficientes (no se llaman lenguas sino
"dialectos") y del otro menos válidas en el "mercado lingüístico" (Bourdieu 1982)
desde los primeros años de la conquista militar y de la dominación cultural con el
proceso de hispanización y occidentalización (por ejemplo en el ámbito religioso).

También en Guinea Ecuatorial, las lenguas autóctonas carecen de reconocimiento y no se clasifican como igualmente aptas para un uso oficial como las lenguas europeas. En el caso concreto de nuestros ejemplos, el uso de dialecto para referirse a las lenguas africanas subraya aún más el carácter negativo de las interferencias de dichas lenguas en el español, cuyo resultado es, precisamente, lo que se conoce como guineo.

En cuarto y último lugar, nos gustaría formular una reflexión crítica en torno a la dialectología hispánica tradicional, que ha surgido en el seno de una ciencia occidental europeizante que, por lo general, no ha tenido en cuenta las variedades excéntricas de la lengua española. También en la lexicografía tradicional, en particular en el DLE (2020), Guinea Ecuatorial sigue teniendo una representación marginal. Aunque el DLE (2020) recoge una serie de acepciones y términos marcados con la etiqueta Guin. (Guinea Ecuatorial), sin lugar a dudas muchos otros quedan excluidos, sea por desconocimiento, sea por falta de interés y empeño. Unos ejemplos los hemos visto y comentado en este artículo; muchos se citan en la bibliografía disponible (por ejemplo, en Quilis \& Casado-Fresnillo, 1995 o en trabajos pioneros como el de González Echegaray, 1959); y otros más quedan por ser descubiertos y estudiados. Consideramos imprescindible luchar por una revisión crítica de las descripciones tradicionales de ciertas variedades del español en el sentido de un acercamiento más global al mundo hispanófono. En concreto, estamos pensando en la importancia de estudiar desde 
una perspectiva más holística las variedades excéntricas del español, que muchas veces son producto de intervenciones coloniales y forman parte de contextos lingüísticos altamente complejos. Queremos poner en relación esta llamada con el concepto del small-scale multilingualism, reflejado también en Guinea Ecuatorial:

Small-scale multilingualism is attested mainly in areas not or relatively recently exposed to Western settlements and Western ideas of nation states and standard language ideologies. Although these areas were drawn into globalization just as settlement colonies were, the absence or recency of large numbers of colonists has resulted in the survival of areas practicing this particular form of multilingualism, which could also be called indigenous multilingualism (Lüpke, 2016, p. 41).

Como añade la autora, solo un acercamiento holístico e interdisciplinario permite reflejar las pautas complejas de las interacciones sociales y lingüísticas presentes en tales entornos (Lüpke, 2016, p. 60). Un acercamiento más neutral permitirá describir con más adecuación las normas propias de escenarios multilingües alejados de los centros dialectológicos tradicionales. En el caso concreto del español de Guinea Ecuatorial, tal reposicionamiento permitiría concebirlo como variedad propia de la lengua, caracterizada por una evolución, adquisición y usos propios, dignos de un estudio independiente y libre de prejuicios y estereotipos. En otras palabras: es necesario describir el español guineoecuatoriano desde su realidad propia y legítima, no a partir de teorías forjadas desde una "cultura lingüística estándar"19. Solo así será posible aumentar también el prestigio que le asignan los propios hablantes, un paso absolutamente imprescindible en el camino hacia el reconocimiento pleno de esta variedad africana de la lengua española.

\footnotetext{
19 "Standard language culture is present in many contexts in the Global South as a reflex of colonialism, in the mainly ex-colonial official languages that occupy the highest position in the new polyglossic linguistic markets there. Many of the areas in question are hotspots of linguistic diversity" (Lüpke, 2015).
} 


\section{OBSERVACIONES FINALES}

La débil representación del léxico guineoecuatoriano en las obras lexicográficas del español es un reflejo de su posición excéntrica en el mundo hispanófono. A pesar del reciente interés científico por Guinea Ecuatorial, por ejemplo, desde la historia, la antropología o los estudios literarios (vid., como ejemplos, Aixelà-Cabré, 2020; Aranzadi Martínez \& Álvarez Chillida, 2020; Riochí Siafá, 2019, 2020), en el ámbito de la lingüística hispánica la variedad guineoecuatoriana del español carece aún de la atención que se merecería. El único país hispanohablante en el África subsahariana ofrece un complejo perfil lingüístico como resultado de la diversidad cultural de su población y los múltiples contactos entre distintas lenguas que han caracterizado su historia. La situación sociolingüística y dialectológica del español en Guinea Ecuatorial se diferencia de otros países de habla hispana y ofrece, por consiguiente, un acercamiento singular al estudio de la lengua española.

En las páginas precedentes, hemos ofrecido un estudio dedicado al léxico español de los guineoecuatorianos, cuyo interés resalta, particularmente, en la combinación de un acercamiento léxico-semántico con otro de tipo teórico-ideológico. En particular, nos hemos interesado por una selección de términos empleados espontáneamente por los propios guineoecuatorianos para describir cómo ellos mismos hablan (o no hablan) o deberían hablar el español. Esto nos ha ofrecido la posibilidad de acercarnos doblemente a esta variedad del español: por un lado, desde el ámbito de la lexicología, analizando el uso propio de cierta terminología metalingüística relacionada con la manera de hablar de los guineoecuatorianos; por otro lado, desde el ámbito de las ideologías lingüísticas, reflexionando sobre las implicaciones teóricas de los usos léxicos observados. Para ello, nos hemos basado en un corpus de entrevistas que destaca por dos características principales: se trata del único corpus lingüístico disponible del habla de los guineoecuatorianos en la diáspora madrileña; y constituye, a nuestro saber, el único corpus sociolingüístico actual del español guineoecuatoriano en general. En concreto, el corpus 
consta de 24 entrevistas semidirigidas, estructuradas según tres criterios de selección: el sexo, el tiempo de estancia de las personas entrevistadas en Madrid (criterio relevante por tratarse de un corpus recogido en un contexto migratorio) y la etnia (característica especial de la sociedad guineoecuatoriana).

A lo largo del artículo, hemos estudiado los siguientes términos: los verbos castizar, inculcar, disparar y chapurrear, y los sustantivos disparate(s) y guineo / guíneo. Algunos se han revelado como especialmente interesantes, dado que muestran el estado deficiente de la lexicografía hispánica por lo que respecta a la inclusión del español guineoecuatoriano. Primero, el verbo castizar, citado ya en estudios anteriores sobre el español de Guinea Ecuatorial y empleado en nuestras entrevistas con el sentido de 'hablar (bien) el español', no está recogido en absoluto en los diccionarios del español (salvo en el DAmer, pero con una definición distinta). Su significado se basa en la semántica del adjetivo castizo / castiza, que subraya lo original y puro del elemento designado. Es por esto que, en el caso de nuestras entrevistas, la acción de castizar se relaciona más con el español peninsular que con el español guineoecuatoriano. Segundo, los términos disparar y disparate(s) constituyen otros guineanismos léxicos, no comentados hasta ahora, que designan una manera peculiar de hablar el español. En concreto, refieren a un uso especial de ciertas palabras (en opinión de algunas personas entrevistadas, un uso inapropiado de los verbos) y a resultados de contactos lingüisticos entre el español y las lenguas africanas, sobre todo, en el español hablado por los fang (fenómenos criticados por las personas entrevistadas). Por lo visto, tanto en disparar como en disparate se podría añadir una acepción adicional a las entradas lexicográficas tradicionales, a modo de ampliación semántica marcada con la etiqueta diatópica de Guinea Ecuatorial. Tercero, sería importante revisar y ampliar las definiciones lexicográficas del término guineo, empleado para denominar la variedad guineoecuatoriana del español. Tanto en este caso como en disparar y disparate sería imprescindible 
evitar connotaciones estereotipadas negativas frente a variedades excéntricas y rasgos no prototípicos, provocadas por una ciencia lingüística dominada por una perspectiva occidental.

En definitiva, el estudio léxico-semántico presentado aquí permite formular conclusiones que van más allá de la lexicología y la lexicografía. A partir de la terminología analizada - y el pequeño excurso sobre los tecnicismos lingüísticos lengua, idioma y dialecto-, se hacen visibles desafíos teóricos que caracterizan la lingüística hispánica en general. Es necesario que intentemos deseuropeizar nuestro modo de pensar, describir e interpretar la diversidad lingüística, sobre todo cuando nos acercamos a regiones geográfica e ideológicamente marginales, es decir, alejadas de los centros de poder tradicionales del mundo hispanófono. Así se podrán reconocer y valorar la gran complejidad sociolingüística y las características dialectológicas propias de variedades tradicionalmente no consideradas, tales como el español de Guinea Ecuatorial. De esta manera, finalmente, será posible equilibrar jerarquías entre centros y periferias y reposicionar variedades excéntricas para llegar a una visión más inclusiva y global del mundo hispanohablante.

\section{BIBLIOGRAFIA}

Aixelà-Cabré, Y. (2020). Colonial Spain in Africa: Building a Shared History from Memories of the Spanish Protectorate and Spanish Guinea. Culture \& History Digital Journal, 9(2), e017. https://doi.org/10.3989/chdj.2020.017.

Aranzadi Martínez, J. R., \& Álvarez Chillida, G. (Coords.) (2020). Guinea Ecuatorial (des) conocida. (Lo que sabemos, ignoramos, inventamos y deformamos acerca de su pasado y su presente) (2 vols.). UNED.

Autoridades $=$ Real Academia Española (1963 [1726-1737]). Diccionario de autoridades (3 vols.). Gredos.

Bengoechea, M. (2001). Gender bias in the Diccionario de la Real Academia Española de la Lengua: the work of the Language Committee (NOMBRA) of the Instituto de la Mujer. Journal of Romance Studies, 1(1), 3-15. https://doi.org/10.3828/jrs.1.1.3

Calvet, L. J. (2005). Lingüística y colonialismo. Breve tratado de glotofagia. Fondo de Cultura Económica de Argentina [1. ${ }^{a}$ ed. en francés de 1974].

Casado-Fresnillo, C. (1995). Resultados del contacto del español con el árabe y con las lenguas autóctonas de Guinea Ecuatorial. En C. Silva-Corvalán (Ed.), Spanish In Four 
Continents. Studies in Language Contact and Bilingualism (pp. 281-292). Georgetown University Press.

Casado-Fresnillo, C. (1998). El léxico español de Guinea Ecuatorial como crisol de continentes. En C. Casado-Fresnillo (Ed.), La lengua y la literatura españolas en África (pp. 69-95). Sociedad Pública "V Centenario de Melilla".

Castillo Barril, M. (1966). La influencia de las lenguas nativas en el español de La Guinea Española. Conferencia pronunciada en el Salón de Actas del Consejo Superior de Investigaciones Científicas el día 2 de abril de 1965. CSIC / Instituto de Estudios Africanos.

Creus, J. (2007). La actitud lingüística de las potencias colonizadoras en el conjunto de África. En G. Nistal Rosique, y G. Pié Jahn (Eds.), La situación actual del español en África. Actas del II Congreso Internacional de Hispanistas en África, celebrado del 11 al 14 de julio de 2006 en Malabo (pp. 33-59). Sial / Casa de África.

DAmer = Asociación de Academias de la Lengua Española (2010). Diccionario de americanismos. https://lema.rae.es/damer/.

DEA = Seco, M., Andrés, O., y Ramos, G. (2011). Diccionario del español actual (2. ${ }^{\text {a ed.) (2 }}$ vols.). Aguilar.

DGLE = Induráin Pons, J. (Dir.) (2009). Diccionario General de la Lengua española (2. ${ }^{a}$ ed.). VOX.

$D L E=$ Real Academia Española / Asociación de Academias de la Lengua Española (2020) Diccionario de la lengua española. https://dle.rae.es/.

$D R A E=$ Real Academia Española (2001). Diccionario de la lengua española (22. ${ }^{a}$ ed.). Real Academia Española.

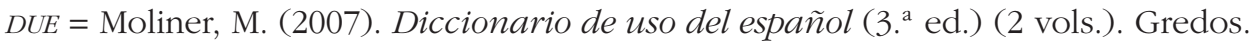

Forgas, E. (2011). El compromiso académico y su reflejo en el DRAE: los sesgos ideológicos (sexismo, racismo, moralismo) del Diccionario. En S. Senz y M. Alberte (Eds.), El dardo en la Academia. Esencia y vigencia de las academias de la lengua española (2 vols.) (pp. 427-457). Melusina.

González Echegaray, C. (1959). Las lenguas de la Provincia Española de Guinea. En Estudios guineos. Vol. I: Filología (pp. 11-71). CSIC / Instituto de Estudios Africanos.

Instituto Nacional de Estadística (2020). Principales series de población desde $1998>$ Total nacional / Comunidades Autónomas > 1.6 / 2.6 Población (españoles/extranjeros) por País de Nacimiento, sexo y año. https://www.ine.es/dynt3/inebase/es/index.htm?type $=$ pcaxis\&path $=/ \mathrm{t} 20 / \mathrm{e} 245 / \mathrm{p} 08 / \&$ file $=$ pcaxis $\& \mathrm{dh}=0 \&$ capsel $=0$ [fecha de consulta: 25.01.2021].

Lipski, J. M. (1986). A New Look at Afro-Hispanic Phonology: The Case of Equatorial Guinea. En O. Jaeggli y C. Silva-Corvalán (Eds.), Studies in Romance Linguistics (pp. 121-135). Foris. https://doi.org/10.1515/9783110878516-010.

Lipski, J. M. (2002). The Spanish of Equatorial Guinea: research on la hispanidad's best-kept secret. Afro-Hispanic Review, 21(1-2), 70-97. 
Lipski, J. M. (2004). The Spanish Language of Equatorial Guinea. Arizona Journal of Hispanic Cultural Studies, 8, 115-130. https://doi.org/10.1353/hcs.2011.0376

Lipski, J. M. (2007). El español de Guinea Ecuatorial en el contexto del español mundial. En G. Nistal Rosique y G. Pié Jahn (Eds.), La situación actual del español en África. Actas del II Congreso Internacional de Hispanistas en África, celebrado del 11 al 14 de julio de 2006 en Malabo (pp. 79-117). Sial / Casa de África.

Lipski, J. M. (2014). ¿Existe un dialecto "ecuatoguineano" del español? Revista Iberoamericana, 80(248-249), 865-882. https://doi.org/10.5195/REVIBEROAMER.2014.7202.

Lüpke, F. (2015). Denorthernising Multilingualism and Multilingualism Research Framing Languages in the North: From the Monolingual Nation State to Acknowledging (Super) Diversity. VOICES from around the world, Special Issue on Multilingualism in the Global South, 3. https://eprints.soas.ac.uk/21945/1/944

Lüpke, F. (2016). Uncovering Small-Scale Multilingualism. Critical Multilingualism Studies, 4(2), pp. 35-74.

Quilis, A., \& Casado-Fresnillo, C. (1995). La lengua española en Guinea Ecuatorial. Madrid: UNED,

Riochí Siafá, J. (2019). Nuevas voces de la literatura de Guinea Ecuatorial. Antología (20082018). Madrid: Diwan Mayrit.

Riochí Siafá, J. (2020). La historia de Guinea Ecuatorial a través de sus protagonistas. Madrid: Diwan Mayrit.

Schlumpf, S. (2018). Guineoecuatorianos en Madrid: actitudes hacia su propio español y el español madrileño. Lengua y migración / Language and migration, 10(2), pp. 7-31. http://lym.linguas.net/Download.axd?type=ArticleItem\&id=190.

Schlumpf, S. (2020a). African languages and Spanish among Equatoguineans in Madrid. Spanish in Context, 17(1), pp. 108-130. https://doi.org/10.1075/sic.18020.sch.

Schlumpf, S. (2020b). El español hablado por los bubis y los fang de Guinea Ecuatorial. Valoraciones desde la comunidad guineoecuatoriana en Madrid. Lengua y migración / Language and migration, 12(1), pp. 103-125. Volumen monográfico (F. Paredes García, \& M. Sancho Pascual, Eds.). http://lym.linguas.net/Download.axd?type=ArticleItem\&id=250.

Schlumpf, S. (en prensa a). Spanisch in Afrika / Afrika in Spanien. Sprachliche Charakteristika von Spanischsprecherinnen und Spanischsprechern aus Äquatorialguinea in Madrid. Romanistisches Jahrbuch (2021).

Schlumpf, S. (en prensa b). ¿África forma parte (o no) de la hispanofonía? Reflexiones glotopolíticas e ideológicas en torno a Guinea Ecuatorial. En L. Becker, J. Del Valle, \& G. Knauer (Eds.), Sprache, Mehrsprachigkeit und sozialer Wandel / Language, Multilingualism and Social Change/Langue, multilinguisme et changement social. Peter Lang.

Vargas, A., Lledó, E., Bengoechea, M., Mediavilla, M., Rubio, I., Marco, A. y Alario, C. (1998). Lo Femenino y lo Masculino en el Diccionario de la Lengua de la Real Academia Española. Ministerio de Trabajo y Asuntos Sociales, Instituto de la Mujer. 
Woolard, K. A. y Schieffelin, B. B. (1994). Language Ideology. Annual Review of Anthropology, 23, 55-82. https://doi.org/10.1146/annurev.an.23.100194.000415.

Yakpo, K. (2010). Gramática del pichi. Ceiba Ediciones/Centros Culturales Españoles de Guinea Ecuatorial.

Yakpo, K. (2013). Wayward daughter: Language contact in the emergence of Pichi. Journal of African Languages and Linguistics, 34(2), 275-299. https://doi.org/10.1515/jall2013-0009.

Yakpo, K. (2016). 'The only language we speak really well': the English creoles of Equatorial Guinea and West Africa at the intersection of language ideologies and language policies. International Journal of the Sociology of Language, 239, 211-233. https://doi. org/10.1515/ijsl-2016-0010.

Zimmermann, K. (2004). El contacto de las lenguas amerindias con el español en México. Revista Internacional de Lingüística Iberorrománica, 2.2(4), 19-29. 